\title{
A piscicultura como atividade agropecuária propulsora do desenvolvimento local e regional: $O$ caso do município de Maripá/PR
}

\author{
Fish farming as a local and regional development driving agricultural activity: The case of \\ Maripá/PR \\ La piscicultura como actividad agropecuaria propulsora del desarrollo local y regional: El caso de \\ la municipalidad de Maripá/PR
}

Recebido: 22/07/2021 | Revisado: 29/07/2021 | Aceito: 31/07/2021 | Publicado: 06/08/2021

Elton Carlos Welter
ORCID: https://orcid.org/0000-0001-6241-6720
Universidade Estadual do Oeste do Paraná, Brasil
E-mail: eltonwelter@gmail.com
Ijean Gomes Riedo
ORCID: https://orcid.org/0000-0001-9159-8703
Universidade Federal da Grande Dourados, Brasil
E-mail: ijeanriedo@gmail.com
Anderson Coldebella
ORCID: https://orcid.org/0000-0002-6615-7583
Instituto Federal de Educação, Ciência e Tecnologia do Paraná, Brasil
E-mail: andersoncoldebella@ @ifpredu.br
Aldi Feiden
ORCID: https://orcid.org/0000-0002-6823-9291
Universidade Estadual do Oeste do Paraná, Brasil
E-mail: aldi.feiden@gmail.com

\section{Resumo}

A piscicultura é uma atividade econômica recente no Brasil. Este trabalho analisou as relações entre os piscicultores familiares e os atores sociais, avaliando ainda os fatores envolvidos sobre o desenvolvimento local no município de Maripá, no Paraná. Concluiu-se que as políticas públicas, a assistência técnica, o associativismo, a industrialização e a articulação proporcionaram o grande crescimento e a intensificação da atividade, fazendo do município uma referência nacional.

Palavras-chave: Aquicultura; Cadeia produtiva; Inovações tecnológicas.

\begin{abstract}
Fish farming is a recent economic activity in Brazil. This paper analyzed the relations between family fishfarmers and the social actors, assessing the factors involved in the local development of Maripá/PR. It was concluded that public policies, technical assistance, associativism, industrialization and articulations provided the great growth and an intensification of the activity, making Maripá a national reference.
\end{abstract}

Keywords: Aquaculture; Productive chain; Technological innovations.

\section{Resumen:}

La piscicultura es una actividad económica reciente en Brasil. Por ello, este trabajo ha analizado las relaciones entre los piscicultores familiares y los actores sociales, evaluando los factores involucrados sobre el desarrollo local en la municipalidad de Maripá, región Oeste de Paraná. De ello, se concluyó que las políticas públicas, la asistencia técnica, el vínculo asociativo, la industrialización y la articulación proporcionaron el gran crecimiento y la intensificación de la actividad, tornando a esa municipalidad una referencia en el ámbito nacional.

Palabras clave: Acuicultura; Cadena productiva; Innovaciones tecnológicas.

\section{Introdução}

A piscicultura é uma das atividades agropecuárias que tem apresentado grande crescimento no Brasil, principalmente nas últimas duas décadas (XX e XXI). Este crescimento foi baseado em vários fatores, como o interesse pela diversificação agrícola, pelo incentivo de políticas públicas e pela ampliação do mercado consumidor. Dados da Pesquisa da Pecuária 
Municipal (PPM) do IBGE (2020) mostram que, no ano de 2019 a aquicultura no Brasil, produziu 599,17 mil toneladas, com maior destaque para a criação de tilápias (aproximadamente 324 mil toneladas) e de tambaqui (101 mil toneladas).

O Paraná destaca-se na produção de peixes, sendo o estado com maior produção de tilápia do país (IBGE, 2020), e a região oeste foi pioneira na criação de peixes em viveiros escavados, pois, no início dos anos 90, a atividade de piscicultura em viveiros escavados, passou a ser uma fonte de renda nas pequenas propriedades rurais (Boscolo \& Feiden, 2007). Leonel et al. (2018) avaliaram que os sistemas de produção, em dois municípios da região oeste do Paraná, são o semi-intensivo e intensivo, e a produtividade média de $29.514 \mathrm{~kg}$ de peixe por hectare/ano de lâmina d’água.

O município de Maripá desponta como um dos municípios com maiores números de produções de tilápias do Brasil, segundo dados da PPM do IBGE (2020). Desde a sua emancipação, em 1993, Maripá tem focado na diversificação da sua produção agropecuária, investindo na piscicultura e na produção de orquídeas. Ela é conhecida como a cidade das orquídeas e tem o peixe como o seu prato típico. O cadeia da piscicultura tem uma grande influência econômica no seu crescimento (LIMA et al., 2005). Desde o início de sua instalação, o município recebeu a assistência técnica para o apoio à piscicultura por parte do Instituto Emater (atualmente Instituto de Desenvolvimento Rural - IDR - do Paraná), e esta ação aliada à criação e atividade da associação de piscicultores, incentivaram a produção aquícola que, nestas duas últimas décadas, tornou-se o município com maiores produtores de peixes em viveiros escavados do país, com produção acima de seis mil toneladas (Paraná, 2016).

O crescimento desta atividade agropecuária na região oeste do Paraná, somado a relevante concentração da estrutura produtiva do município de Maripá e a integração com agentes sociais (transformadores), com potencialidade para a coordenação de ações coletivas, indicam a existência de estreitas redes de relacionamentos e cooperação entre os atores da cadeia de produção (Feiden et al., 2018). Diante disso, para avaliar a importância do crescimento da atividade de piscicultura, este trabalho buscou analisar as relações entre os atores e os principais fatores envolvidos com o desenvolvimento local e regional. Este estudo teve por objetivo identificar os principais processos da atividade de piscicultura, desde a emancipação do munípio. Enfatiza-se que no município estudado, a atividade é predominantemente de exploração familiar e que proporcionou desenvolvimento social e econômico, perfazendo nos cenários regionais e nacional, como o município com maior produtividade de peixes por área em viveiros escavados.

\section{Metodologia}

O levantamento de dados a campo foi realizado com dois grupos envolvidos na atividade, sendo o primeiro constituído por 20 piscicultores (de um total de 98 produtores), escolhidos aleatoriamente, a partir do cadastro municipal da Emater; e o segundo grupo, constituído por 13 agentes sociais com envolvimento na atividade da piscicultura, selecionados entre os diversos elos da cadeia produtiva da piscicultura, atuantes no município: como agentes de crédito, extensão rural e fiscalização ambiental, representantes de entidades de classe, representantes comerciais, do comércio de insumos, serviços, equipamentos e comercialização. Foi utilizada a pesquisa exploratória e documental, conforme Gil (2010).

A delimitação temporal do estudo, compreendeu o período entre a emancipação do município em 1993 até o ano de 2015, divididos em três fases da piscicultura, sendo: a primeira, o período de 1993 até 2003 (10 anos - fase inicial); a segunda, o período de 2004 a 2009 (6 anos - fase de organização); e a terceira, o período de 2010 a 2015 (6 anos - fase de profissionalização). Essas definições dos espaços temporais foram estabelecidas por consultas documentais.

A pesquisa documental foi realizada em bases de dados de órgãos federais e estaduais, bem como análise de documentos científicos elaborados sobre a temática. A aplicação dos questionários para os dois grupos, ocorreu entre os meses de julho a setembro de 2017. Em seguida, os dados foram tabulados e sistematizados em planilhas eletrônicas, para análises estatísticas utilizando a ferramenta estatística IBM SPSS Statistics ${ }^{\circledR}$. Posteriormente, foram elaborados gráficos, tabelas e 
quadros explicativos abordando os resultados. Aplicou-se a análise multivariada por meio de Análise de Componentes Principais (PCA), avaliando as dimensões com a linguagem de programação R (R Core Team, 2013) e utilizando o pacote complementar FactoMiner (Le et al., 2008).

\section{Resultados e Discussões}

Os resultados da pesquisa mostram que a atividade teve um crescimento muito importante na economia do município e foi pujante na adoção de tecnologias para o setor, principalmente para a produção da espécie tilápia (Oreochromis niloticus), que concentra a grande maioria da produção. A Figura 1 mostra que a piscicultura contribui com 7\% de toda a produção agropecuária, destacando-se como a terceira atividade pecuária, e quinta atividade rural, em expressão econômica, e entre as espécies criadas, a tilápia representa mais de $99 \%$ do valor bruto da produção agropecuária municipal (Paraná/SEAB, 2016a; Paraná/SEAB, 2016b).

Figura 1: A. Importância econômica da piscicultura na produção agropecuária do município de Maripá/PR; B. Principais espécies criadas na piscicultura.

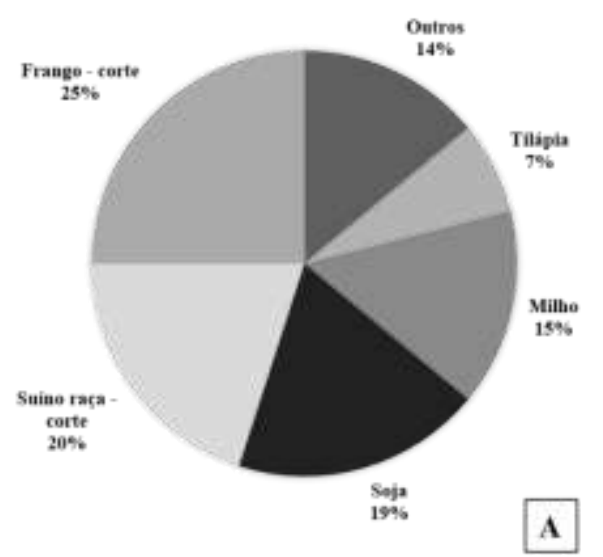

\begin{tabular}{|c|c|c|c|}
\hline \multicolumn{4}{|c|}{ Valor Brute da Produçãe de Maripà 2016} \\
\hline Espécie & KG & Valor RS & \\
\hline Bagre & 22.000 & $110.400,00$ & \\
\hline Carpa & 12.000 & $67,080,00$ & \\
\hline Curimba & 18.600 & $117.738,00$ & \\
\hline Piauçu & 32.500 & $222.500,00$ & \\
\hline Tulápia & 7.220 .00 & $32.490 .000,00$ & \\
\hline Total & 7.305 .100 & $33.007 .718,00$ & \\
\hline Paranả & & & B \\
\hline
\end{tabular}

Fonte: A) Elaborado pelos autores a partir de Paraná (2016a); B) Paraná/SEAB (2016b).

A atividade iniciou em 1993, quando foi emancipado o município, com o apoio estadual por meio do Instituto Emater (atualmente Instituto de Desenvolvimento Rural - IDR - do Paraná), que destacou um técnico para atuação no escritório local, e de acordo com os piscicultores, a fase inicial (que durou até o ano de 2003) foi caracterizada por um período de maiores dificuldades para a produção comercial, o que pode ser demonstrado pelos resultados da Figura 2.

A produtividade média por hectare/ano, deste período, foi bastante baixa, de três toneladas por hectare, pelo fato de que muitos produtores produziam apenas para sua subsistência e não para comercialização. Lembra-se que em 1996 foi implantada uma Unidade de Observação e Pesquisa no município, que serviu para realização de testes e treinamento dos piscicultores (Emater, 2016).

A partir de 2004, a prefeitura municipal de Maripá e a Emater (IDR) apoiaram os produtores comerciais até 2009, configurou-se a fase de organização. Neste período, o número médio de piscicultores diminuiu, mas ampliou a área de cultivo e a produtividade média, que elevou para 22,6 ton/ha (tonelada/hectare). Assim, mais de 50\% dos piscicultores afirmaram, que a atividade apresentou menor dificuldade de produção (cultivo, gestão rural, entre outros).

No último estágio, a fase da profissionalização, entre 2010 e 2015, o município quase duplicou sua área de lâmina d’água e atingiu uma produtividade média de 47 ton/ha, e a grande maioria dos piscicultores afirmaram ainda menor dificuldade para ter sucesso na atividade (cultivo, gestão rural, escoamento, entre outros). 
Figura 2: A. Produção média anual por período estudado; B. dificuldades encontradas pelos piscicultores nas três fases avaliadas.

\begin{tabular}{|c|c|c|c|c|}
\hline Periodo & Piscicultores & Làmina d'água & Produçio medla & Produtividadt \\
\hline (anos) & (média) & (ha) & Anual (ton) & (ton/ha) \\
\hline 1993 a 2003 & 81 & 35 & 105 & 3 \\
\hline 2004 a 2009 & 39 & 47,9 & 1.083 & 22,6 \\
\hline 2010 a 2015 & 63 & 86,9 & 4.081 & 47 \\
\hline onte: Adaptad & timto Fent & lade Mnnicinsl & píPR.2016 & sina \\
\hline
\end{tabular}

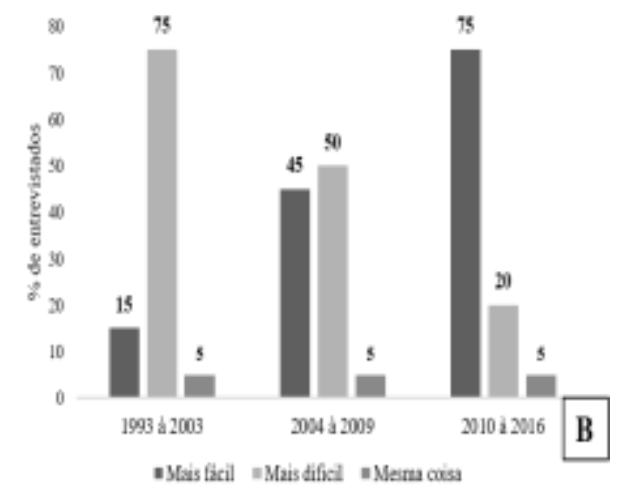

Fonte: A) Adaptado de Instituto Emater (2016);B) Elaborado pelos autores.

A intensificação e o sucesso da atividade no municipio, pode ser explicado pelo grande aumento do número de iniciantes (novos entrantes) na atividade, com 50\% dos piscicultores tendo iniciado suas atividades ao longo dos anos (Figura 3). Entre os principais motivos que proporcionaram este aumento na produção, destacam-se a rentabilidade da atividade (70\%), a busca por diversificação e a oportunidade de investimento em uma nova atividade econômica (ambos com 15\%).

Figura 3: A. Experiência do piscicultor na atividade (anos); B. Motivos pelo qual investiu na piscicultura (\%)

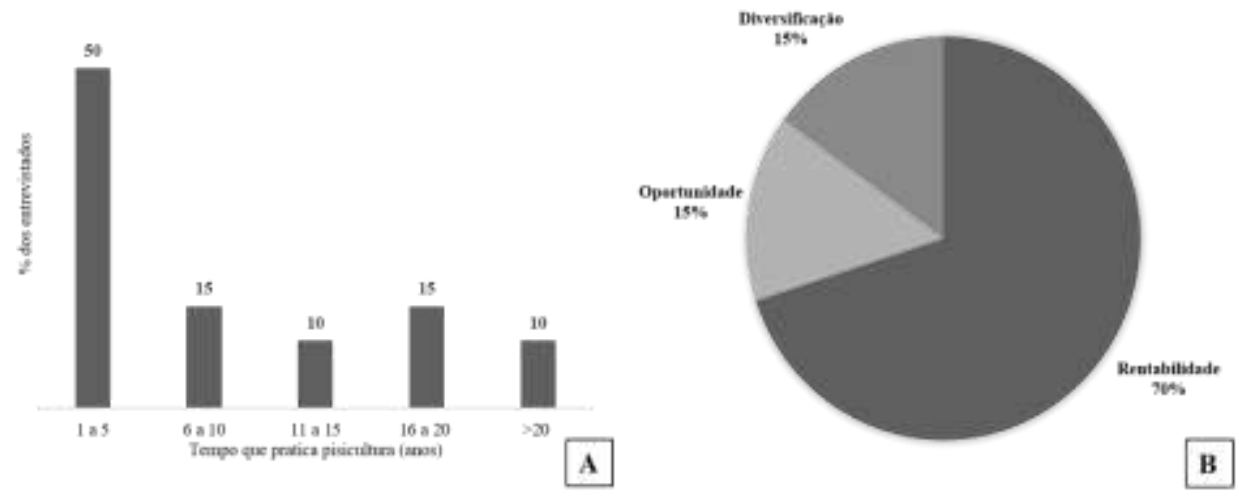

Fonte: Elaborado pelos autores.

Ao analisar a rentabilidade da atividade piscícola, os resultados do levantamento junto aos piscicultores (Figura 4), o estudo mostrou que a renda familiar global na maioria dos entrevistados ultrapassa os $50 \%$ da renda total da propriedade rural, e que mais de um terço destes é superior a 90\%, o que mostra que a atividade é bastante lucrativa, e que traz perspectivas favoráveis a novos investimentos, seja para aumentar a área de criação ou manter a área e intensificar ainda mais a produção, que é a intenção de mais $70 \%$ dos entrevistados.

O designio de investir em ampliação de área e intensificação da atividade (Figura 5), focada na utilização da mão-deobra familiar, é uma necessidade da agricultura brasileira. Segundo Lopes e Contini (2012) e Riedo (2017), os agricultores brasileiros precisam contar com novas alternativas de mecanização, automação e tecnologias de precisão que potencializam as produções, pensando na redução de desperdícios e na sustentabilidade. Siqueira (2017) relata a possibilidade de aumentar a disponibilização de alimentos, fator necessário para os desafios da sobrevivência humana e do desenvolvimento sustentável, aplicando melhores/boas práticas e apoiando a inovação e o empreendedorismo na sociedade.

A opção dos agricultores pela diversificação da sua produção agropecuária, contribuiu com o desenvolvimento local, comprovando a afirmação de Schneider (2010), que afirma que, em nível da economia local e do território, os efeitos da 
diversificação são perceptíveis em face das caracteristicas economicas locais, podendo ser diversificado e criando ambientes favoráveis à integração setorial entre agricultura, comércio, indústria e serviços (Silva et al., 2020).

Figura 4: A. Renda familiar global advinda da atividade de piscicultura (\%); B. Perspectivas de ampliação do investimentos em piscicultura.

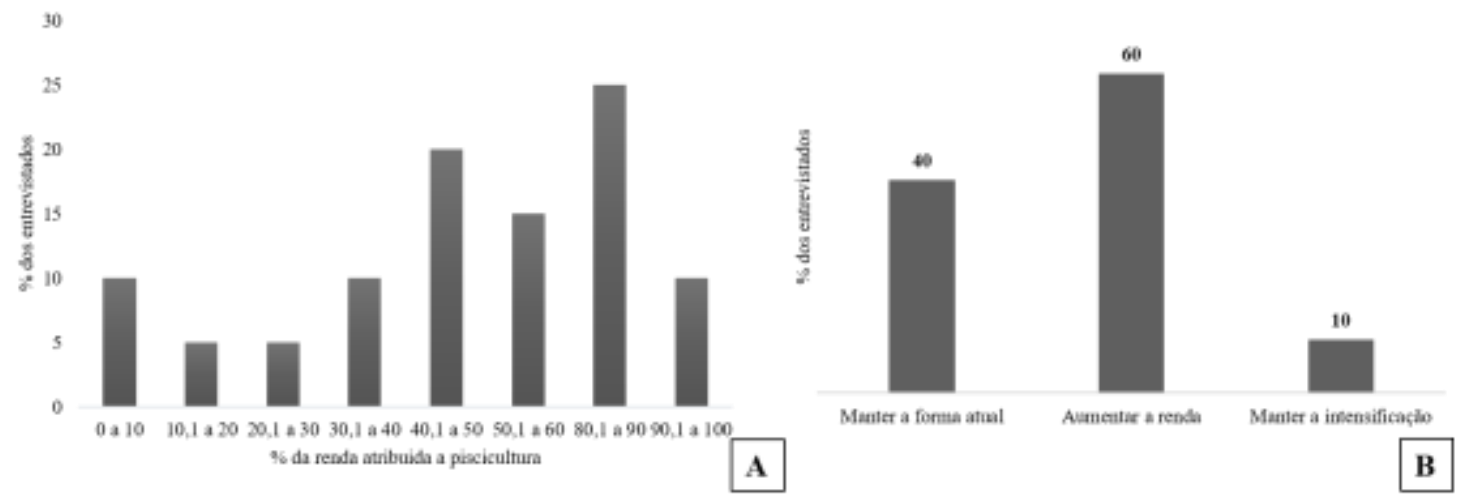

Fonte: Autores.

Este comportamento de investir na atividade foi demonstrada pela grande variação no grau de intensificação da atividade existente no município (Figura 5), visto que enquanto alguns piscicultores já utilizam altas densidades de estocagem, como 10 ou mais peixes por $\mathrm{m}^{2}$ de lâmina d'água, a maioria ainda utiliza densidades menores, de 5 a 8 peixes por $\mathrm{m}^{2}$, sem necessidade de ampliação do uso de mão-de-obra externa à propriedade, utilizando apenas a mão-de obra da família, mas mecanizando e automatizando processos, principalmente na alimentação dos peixes e na aeração dos viveiros.

Figura 5: A. Grau de intensificação da produção por densidade de estocagem de peixes por metro quadrado de lâmina de água; B. Utilização da mão-de-obra familiar na atividade de piscicultura.
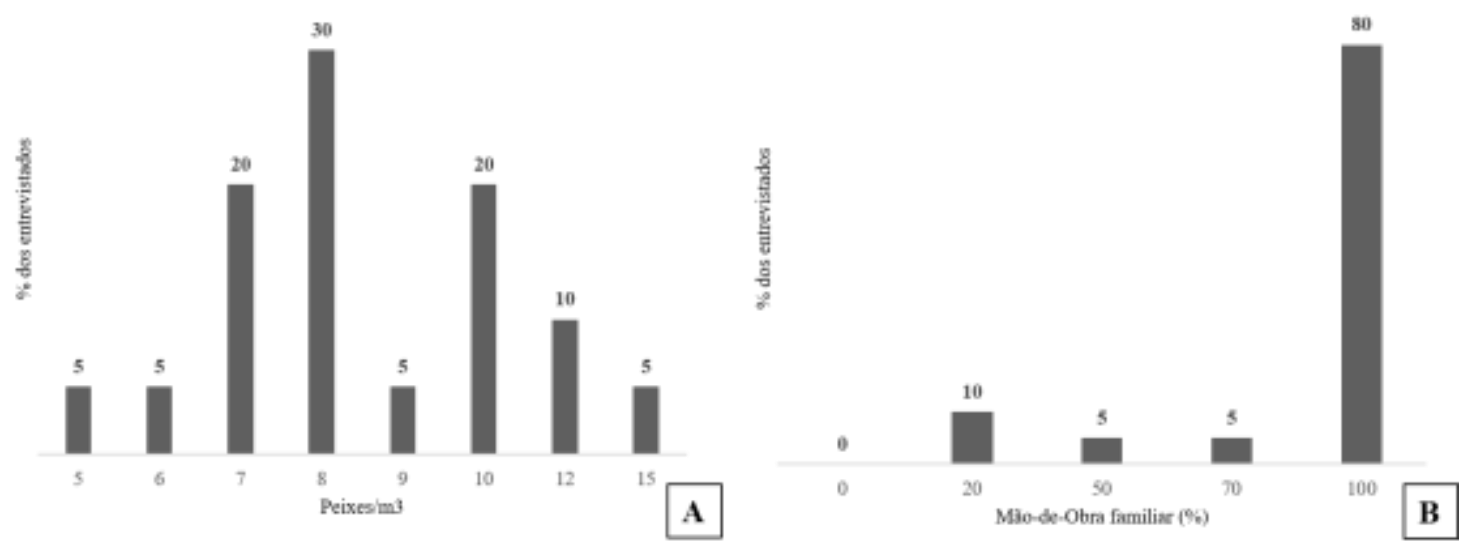

Fonte: Autores.

Leonel et al. (2018), estudando a piscicultura nos municípios Toledo e Marechal Cândido Rondon, vizinhos ao município Maripá, comprovaram a predominância do uso da mão-de-obra familiar. Os resultados dos autores ainda mostraram que os piscicultores enquadram-se numa categoria social de agricultores familiares modernizados, que possuem pouca área de terra, mas que direcionam sua produção para a agroindustrialização, e mantêm a força de trabalho da família como seu principal fator produtivo. 
A organização dos piscicultores, desde o início (1993), foi um determinante propulsor ao desenvolvimento da atividade, e em 1997, foi constituída formalmente a Associação do Aquicultores de Maripá (AQUIMAP), que até a atualidade (2021) é muito ativa e enquadra-se como responsável de crescimento por 92,31\% dos piscicultores entrevistados (Figura 6).

Figura 6: Grau de importância da associação manifestado pelos piscicultores para o desenvolvimento da piscicultura no município de Maripá.

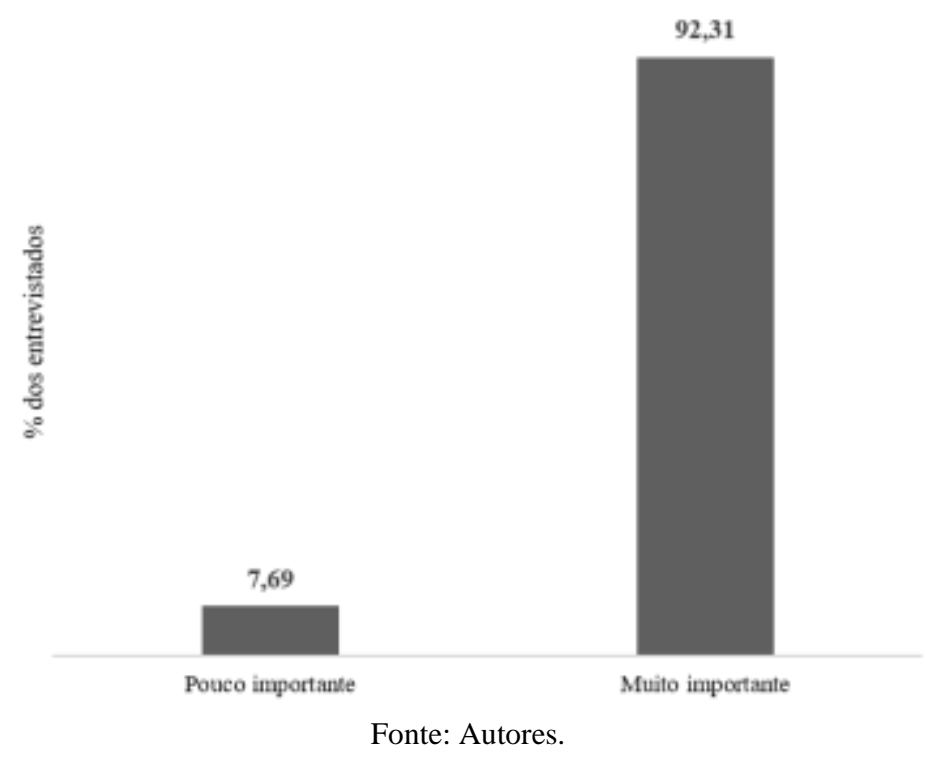

A prefeitura municipal também incentiva a associação, que é a responsável pela organização anual do "Seminário Estadual de Piscicultura" e pela elaboração dos produtos a base de peixes que são servidos na tradicional Festa das Orquídeas e do Peixe de Maripá, que acontece anualmente em agosto. Pasini (2013) afirma que um dos benefícios percebidos pela coletividade, foi a possibilidade de produção de peixes em escalas maiores, bem como a comercialização de um produto de melhor qualidade. Ainda, por influência da associação, foi criada a Lei Municipal que, em 2005 introduziu o peixe na merenda escolar no mínimo uma vez por semana, fomentando assim, a comercialização de peixes na cidade.

Ao analisar a percepção dos piscicultores, sob a influência das políticas públicas na organização da cadeia produtiva, tanto ao incentivo ao desenvolvimento da atividade quanto ao crescimento da produção aquícola, destaca-se a dimensão assistência técnica de maneira expressiva (Figura 7). Os resultados mostram que a assistência técnica foi determinante para $85 \%$ dos entrevistados iniciar na atividade, e para aqueles que já estavam na atividade o número subiu para $90 \%$ dos piscicultores.

Dito isso, a análise revelou que o papel da extensão é fundamental para o desenvolvimento de uma atividade ou região, o que corrobora com Abramoway (1998), que afirma que os extensionistas, um agente social (ou de desenvolvimento, ou transformador), são partes essenciais de um amplo processo de mobilização social. 
Figura 7: A. Importância da assistência técnica para iniciar na atividade de piscicultura. B. Garantia de ter assistência técnica para manter a atividade de piscicultura.

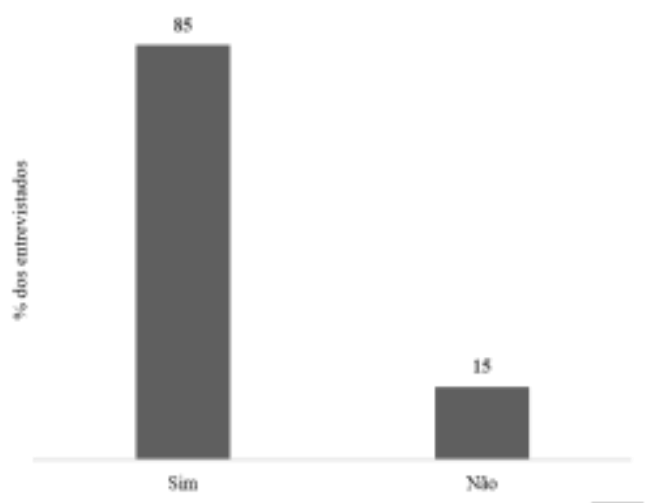

A

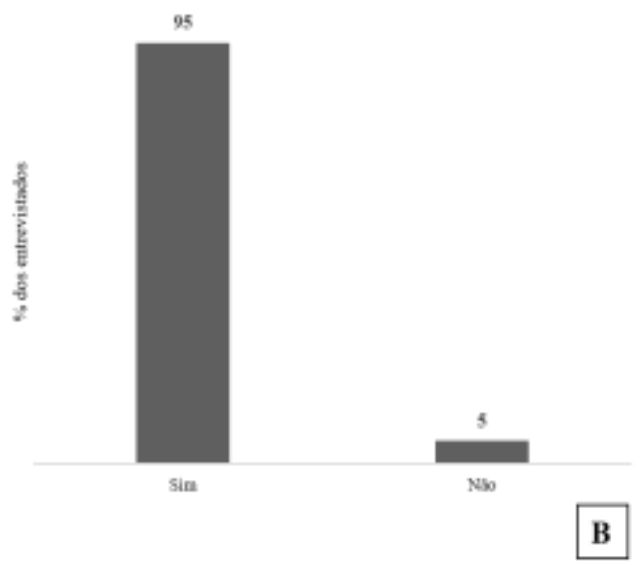

B

Fonte: Autores.

Ao realizar compreender as Análises de Componentes Principais (PCA), os piscicultores e agentes sociais atuantes no município de Maripá/PR, mostraram respostas positivas para a influências das diferentes variáveis estudadas (figura 8).

Figura 8: Respostas da análise dos componentes principais: A. Foco dos piscicultores e agentes sociais; B. Principais fatores que contribuíram para o desenvolvimento da piscicultura no município de Maripá/PR.

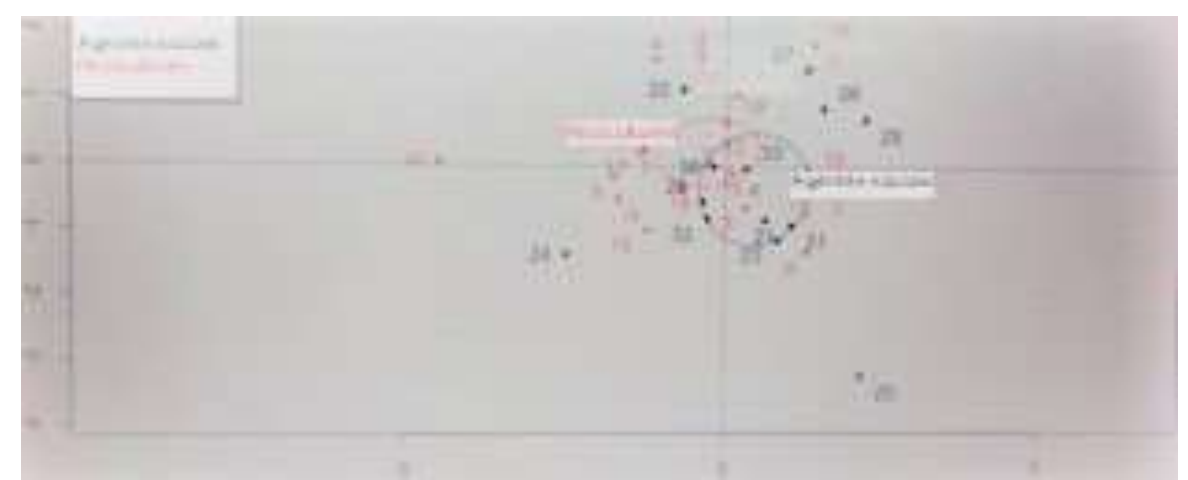

A

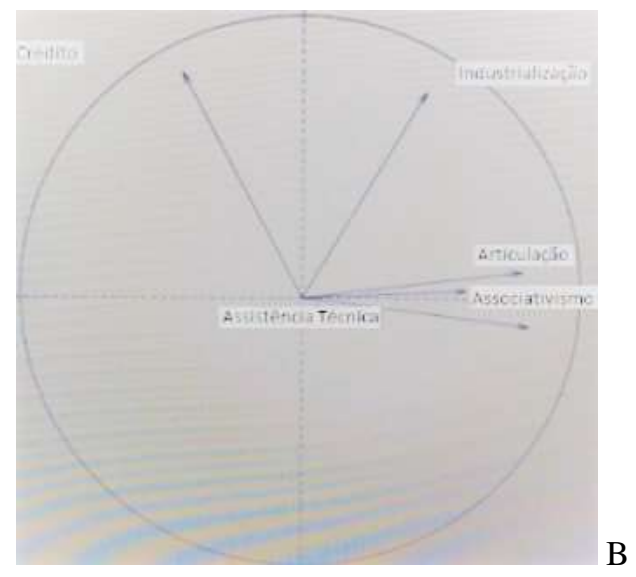

Fonte: Autores.

As respostas dos agentes sociais de forma mais concentrada, mostraram uma articulação mais intensa e positiva dos fatores, como crédito e financiamento para a produção, apoio técnico e extensão aquícola, ampliação do mercado consumidor, 
notadamente da demanda para industrialização, e também, importância da organização associativa dos produtores. Em uma análise segregada, da importância dos fatores envolvidos no desenvolvimento da cadeia, analisando conjuntamente os dois segmentos da cadeia, ou seja, os piscicultores e os agentes sociais (Figura 8), a PCA demonstrou que o crédito foi o fator mais preponderante, seguido da capacidade e demanda de industrialização do pescado produzido, mas com grande influência também da assistência técnica e da articulação entre os grupos sociais.

Nesta análise, observou-se que o associativismo não apresentou tanta importância, o que pode ser explicado pelas respostas dos agentes sociais, visto que na análise anterior, mostrada na Figura 7, ao avaliar apenas as opiniões dos piscicultores, a assistência foi fundamental para iniciar e se manter na atividade.

Estes resultados corroboram com o que já diziam Martins et al. (2001), que já identificavam um forte potencial para a implementação de políticas públicas no sentido de coordenar a piscicultura na região, com assistência técnica e financeira. $\mathrm{O}$ crescimento da atividade voltada à industrialização, notadamente na última década, é demonstrada pelo estudo de Chidichima et al. (2018) ao analisar 17 indústrias de processamento de pescado da região oeste do Paraná e do Baixo Iguaçu (Paraná), e da análise da estruturação de um Arranjo Produtivo Local (APL) da piscicultura na região, realizada por Feiden et al. (2018), que apresentava uma caracterização da cadeia de produção de filé de tilápia, na região oeste do Paraná, bem como uma análise das relações sociais, em forma de rede, entre os principais atores que compõem a cadeia produtiva da piscicultura.

A importância do crédito no desenvolvimento da atividade, pode ser comprovada pelos diversos programas federais e estaduais, além do apoio local, principalmente pela disponibilização de crédito de longo prazo para investimentos em construção de viveiros e aquisição de equipamentos, bem como crédito para custeio da produção. Entre os programas federais destacam-se o Programa Nacional de Fortalecimento da Agricultura (Pronaf), o Programa Mais Alimentos, e a partir de 2012, o Plano Safra da Pesca e Aquicultura, que criou linhas de crédito para aquicultores investir em novas estruturas, equipamentos e máquinas. Todas estas linhas de crédito para investimento e custeio foram alocadas aos piscicultores por meio de bancos públicos, como Banco Nacional de Desenvolvimento Econômico e Social (BNDES), Banco do Brasil (BB), Caixa Econômica Federal (CEF), e privados como os bancos cooperativos, a exemplo do Sicredi e Cresol, e instituições conveniadas, como o Banco Regional de Desenvolvimento do Extremo Sul (BRDE), que operou muito intensamente na região, no fomento a investimentos para estruturar a cadeia da piscicultura e industrialização do pescado.

Esta importante ação de disponibilidade de crédito é apontada pelos estudos de Costa et al. (2014) sobre os investimentos do BNDES para a região sul e por Sidônio et al. (2012), ao analisar o panorama da aquicultura brasileira e a necessidade de investimentos para o setor. Outras regiões brasileiras nem sempre conseguem mobilizar os piscicultores no acesso ao crédito para investimentos e custeio, como relatam Araújo et al. (2015) os quais mostraram que, entre 2000 e 2010 , apenas 0,93\% dos recursos do Fundo Constitucional de Financiamento do Norte (FNO), aplicados no setor agropecuário paraense foram alocados em projetos de aquicultura.

Os autores acima ainda relataram que as causas que levaram a este baixo acesso foram resultantes da combinação de fatores como o baixo nível de organização dos produtores, assistência técnica incipiente e pouco especializada em aquicultura, licenciamento ambiental demorado, além da burocracia durante o processo de contratação das operações de crédito.

Essa articulação em redes de produtores, existente em Maripá, entre os diferentes agentes, envolvendo as políticas públicas, o uso dos recursos naturais e a apropriação das políticas públicas para desenvolver a atividade da piscicultura, reforça os resultados obtidos por Boisier (1996), que afirma que o desenvolvimento local ocorre devido a densa articulação entre os segmentos que atuam na cadeia produtiva, e que nestas duas décadas, tem proprocionado o crescimento da atividade.

Assim, a piscicultura de Maripá, atualmente considerada uma das mais consolidadas do país e referência regional e nacional, sendo inclusive o município que apresenta a maior produtividade por área de lâmina de água do país, mostra que pode sustentar um desenvolvimento em bases sólidas, com uma densa articulação entres os setores envolvidos, e que a visão de 
longo prazo dos gestores públicos, aliado à execução de políticas públicas focadas no desenvolvimento sustentável, promove o desenvolvimento local e regional.

\section{Conclusões}

O município de Maripá é atualmente uma referência regional e nacional na piscicultura, pelo fato de ter investido na atividade como uma forma de diversificação da agropecuária. A articulação dos atores e as fases de apropriação da atividade foram determinantes para o sucesso da cadeia produtiva da piscicultura. Evidencia-se que houve captação de políticas públicas específicas para a piscicultura, tanto de crédito como de assistência técnica, e como resultado da efetividade destas políticas houve o envolvimento de grandes mercados da industrialização do pescado.

Neste contexto, o estudo mostrou que houve um grande crescimento e intensificação da piscicultura em Maripá/PR, principalmente na última década estudada, em função da grande rede de relacionamentos de promoção de sinergias entre todos os atores envolvidos da cadeia produtiva.

Isto mostra que quando há um planejamento com foco de médio e longo prazo, ocorre o desenvolvimento local e regional sólido e perene. Faz-se necessário cada vez mais compreender as inter-relações entre o crescimento econômico e os conceitos de desenvolvimento, objetivados ao pensar nos produtores rurais e nos agentes sociais, para constituir sistemas institucionais em visões holísticas de cada cadeia produtiva brasileira (Riedo \& Feiden, 2021).

Por fim, conclui-se neste estudo, que a composição produtiva da cadeia da piscicultura de Maripá/PR pode servir de molde para o desenvolvimento de outras cadeias produtivas piscícolas brasileiras. Isto posto, propoem-se como estudos futuros a realização de estudos comparativos de dados, resultados desta pesquisa, com outras regiões do país.

\section{Agradecimentos}

Os autores agradecem o Programa de Pós-graduação em Desenvolvimento Rural Sustentável (PPGDRS) da Universidade Estadual do Oeste do Paraná (UNIOESTE), ao Instituto Federal do Paraná (IFPR) e à Universidade Federal da Grande Dourados (UFGD).

\section{Referências}

Araújo J. G., Santos M. A. S., Rebello F. K., Oliveira C. M., Costa A. D. (2015). Crédito rural para aquicultura: uma análise do Fundo Constitucional de Financiamento do Norte no estado do Pará. Revista Eletrônica em Gestão, Educação e Tecnologia Ambiental. 19, 553-562.

Abramoway, R. (1998). Agricultura Familiar e Serviço Público: Novos Desafios Para a Extensão Rural. Cadernos de Ciência \& Tecnologia. $15,137-157$.

Boisier, S. (1996) Em busca do esquivo desenvolvimento regional. Entre a caixa-preta e o projeto político. Planejamento e políticas públicas, 13 , 111-147.

Boscolo, W. R., \& Feiden, A. (2007). Industrialização de Tilápias. GFM.

Chidichima, A. C., Feiden, A., \& Signor, A. (2018). Industrialização de tilápia. Processo e métodos de transformação, desafios e perspectiva para o setor. Beau Basin: Novas Edições Acadêmicas. 89p.

Costa, A. M. C., Fuchsloch, A. V. R., Gusmão, A. M. F. R., \& Paula, T. A. S. (2014) Parcerias para o desenvolvimento: o apoio do BNDES para a Região Sul por meio da Área de Operações Indiretas e instituições financeiras credenciadas 2008-2013. BNDES p.163-179. 2014.

EMATER (2016). Piscicultura/Maripá: Dados de 1993/2012. Emater.

Feiden, A., Ramos, M. J., Chidichima, A. C., Schmidt, C. M., Fiorese, M. L., \& Coldebella, A. (2018) A cadeia produtiva da tilápia no oeste do Paraná: uma análise sobre a formação de um arranjo produtivo local. Redes. 22238-263.

Gil, A. C. Métodos e Técnicas de Pesquisa Social. Atlas, (5a ed.),

IBGE - Instituto Brasileiro de Geografia e Estatística (2020). Pesquisa da Pecuária Municipal. <https://sidra.ibge.gov.br/pesquisa/ppm/quadros/brasil/2019>.

Le, S., Josse, J., \& Husson, F. (2008) FactoMineR: An R Package for Multivariate Analysis. Journal of Statistical Software, 25, 1-18. 
Research, Society and Development, v. 10, n. 10, e95101018565, 2021

(CC BY 4.0) | ISSN 2525-3409 | DOI: http://dx.doi.org/10.33448/rsd-v10i10.18565

Leonel, A. P. S., Martins, M. I. E. G., Feiden, A., Feiden, A., \& Silva, A. M. (2018). Perfil de pisciculturas nos municípios de Toledo-PR e Marechal Cândido Rondon-Pr. In: Investigação Científica e Técnica em Ciência Animal. Atena, p.109-119.

Lima, D., P., Schallenberger, E., \& Lima, E. (2005). Festas típicas gastronômicas de cidades da região oeste do Paraná e a influência econômica que representaram para economia regional. Tecnologia \& Humanismo. 19, 127-142.

Lopes, M. A., \& Contini, E. (2012). Agricultura, Sustentabilidade e Tecnologia. Embrapa.

Pasini, A. H. (2013). A ação coletiva como forma de agregação no sistema agroindustrial da aquicultura de Maripá-PR. Dissertação de mestrado: Universidade Estadual do Oeste do Paraná, Toledo.

Martins, C. V. B., Oliveira, D. P., Martins, R. S., Hermes, C. A., Oliveira, L. G., Vaz, S. K., Minozzo, M. G., Cunha, M., \& Zacarkin, C. E. (2001). Avaliação da Piscicultura na Região Oeste do Estado do Paraná. Boletim do Instituto de Pesca. 27, 77-84.

PARANÁ (2016). VBP 2016 - Relatório Municipal. P. 665 <http://www.agricultura.pr.gov.br/arquivos/File/deral/RelMunicipal20162versao.pdf>.

Paraná/SEAB - Secretaria De Estado Da Agricultura E Abastecimento (2016a). Gráficos Municipais Referentes ao Valor Bruto da Produção Rural 2016. P. 229. <Http://Www.Agricultura.Pr.Gov.Br/Arquivos/File/Deral/Graficos_Munic Ipais_VBP_Graregi_2016Finalp Arapublicac Ocorrigido.Pdf>.

Paraná/SEAB - Secretaria De Estado Da Agricultura E Abastecimento (2016b). Versão Definitiva do Levantamento da Produção Rural Paranaense por Município. p. 662. 2014. 〈http://www.agricultura.pr.gov.br/arquivos/File/deral/Relatorio Municipal2versao.pdf >

R CORE TEAM R (2013). A language and environment for statistical computing. Viena: R Foundation for Statistical Computing.

Riedo, I. G. (2017). Desenvolvimento da piscicultura em pequenas propriedades rurais: contexto da Tríplice Hélice. Dissertação de mestrado: Universidade Federal da Grande Dourados.

Riedo, I. G. \& Feiden, A. (2021). Triple Helix Theory: What does the research of the Brazilian Postgraduate Programs present?. Research, Society and Development, 10(9), e14410918036. https://doi.org/10.33448/rsd-v10i9.18036

Sidonio, L., Cavalcanti, I., Capanema, L., Morch, R., Magalhães, G., Lima, J., Burns, V., Alves Jr., A. J. \& Mungioli, R. (2012). Panorama da Aquicultura no Brasil: Desafios e Oportunidades. BNDES Setorial, n.35, p. 421-463.

Silva, F. N. L., Pereira, A. S., Oliveira, L. A. de A., Oliveira, L. C. de, Macedo, A. R. G., Quadros, M. L. A. de, Mendonça, R. C., \& Castro, N. M. de S. (2020). Rural extension methodologies applied to aquaculture: a parallel between theory and practice. Research, Society and Development, 9(8), e245984168. https://doi.org/10.33448/rsd-v9i8.4168

Siqueira, T. V. (2017). Aquicultura: A Nova Fronteira Para Aumentar a Produção Mundial de Alimentos de Forma Sustentável. IPEA Boletim Regional, urbano e Ambiental. 17. 54-60.

Schneider, S. (2010). Reflexões sobre diversidade e diversificação: agricultura, formas familiares e desenvolvimento rural. Ruris. 4, 85-131. 